\title{
Medical and Psychosocial Profile of Geriatric Population in Field Practice Area of Nanded, India
}

\author{
Mohammed Ubaidulla ${ }^{1}$, Inamdar I.F. ${ }^{2}$, Aswar N.R ${ }^{3}$, Doibale M.K. ${ }^{4}$, \\ Narkhede M.G. ${ }^{5}$ \\ 1-Assistant Professor - Department of General Medicine \\ 2-Assistant Professor-Department of Community Medicine \\ 3-Associate Professor-Department of Community Medicine \\ 4-Professor \& Head-Department of Community Medicine \\ 5-Professor Department of Medicine, GMC Dhule \\ Institute: Dr. S.C. Government Medical College, Nanded, Maharashtra, India
}

\begin{abstract}
BACKGROUND: Geriatric health problems are emerging as a major public health concern. Change in socio-economic profile and various health problems adversely affect an individual's way of life during old age. The number of persons above the age of 60 years is fast growing, especially in India. India as the second most populous country in the world has 76.6 million people at or over the age of 60, constituting above $7.7 \%$ of total population. The relatively faster increase in the elderly population will contribute to a morbidity and higher dependency ratio of the population in the non-productive age group. OBJECTIVES: To study the medical and psychosocial problems among geriatric population. METHODOLOGY: The present cross sectional study was conducted at urban health training centre, Shivaji nagar, Nanded, catering health care services to around 59586 populations of all ages. A multi diagnostic camp based approach was used to study the health status of the geriatrics. Study of medical and psychosocial problems among population aged 60yrs and above was carried out using pre designed pre tested questionnaire. RESULTS: In the present study, 354 subjects above 60 years were studied. There were 198 males and 156 females. Around $73 \%$ of the patients belonged to the age group of 60-69 years. $74 \%$ respondents were illiterate. The morbidity pattern showed that hypertension was seen in 43\%. $27 \%$ were suffering from COPD. $2 \%$ were suffering from Tuberculosis. Osteoarthritis was seen in $28 \%$ subjects. $62 \%$ of the study subjects were suffering from senile cataract. $78.55 \%$ subjects were suffering from emotional problems. $40.90 \%$ males were smokers and $38.50 \%$ of the males were consuming alcohol. $34.84 \%$ of the males and $42.30 \%$ females were addicted to tobacco chewing. The health facility used by the study subjects was mainly the Urban Health Training centre (87\%) followed by private practitioners (13\%). $44.9 \%$ were having sad attitude towards their lives. $2 \%$ were related to social organization. $52 \%$ subjects have good familial relationship. 58\% have impaired hearing, amongst them $1 \%$ used hearing aids. $32 \%$ were irritated easily. $68 \%$ had disturbed sleep pattern. $9 \%$ people feel confident in crisis .Conclusions: The financial and social needs of the elderly should be fulfilled by preserving traditional joint family system. Senile cataract was the commonest illness followed by HTN. Addictions such as alcohol and smoking were common especially among males whereas tobacco chewing was common among females. Special geriatric services should be started in the hospitals as the majority of the aged have one or more health-related problems. The aged persons should be involved in social activities to avoid loneliness among them.
\end{abstract}

Key Words: Elderly, Morbidity, Geriatric health, economic aspect, Geriatric Care.

\section{Introduction}

Elderly or old age consists of ages nearing or surpassing the average life span of human beings. The boundary of old age cannot be defined exactly because it does not have the same meaning in all societies. Government of India adopted 'National Policy on Older Persons' in January, 1999. The policy defines 'senior citizen' or 'elderly' as a person who is of age 60 years or above ${ }^{(1)}$. 'Aging of the Population' characterized by the relatively rapid increase of the aged population i.e. the population aged 60 years and above ${ }^{(2)}$. Aging is a natural process. In India, the 60 plus population in 1951 was just $5.43 \%$ that had gone up to more than $7.7 \%$ in $2001^{(3)}$. Due to improved health care services there is decreased infertility and mortality and these lead to increased geriatric population both in developed as well as developing countries. As people become older the functioning and adaptability of the tissues and different organs decline and chances of suffering of geriatric populations are more. Geriatric populations suffer both from communicable and non-communicable diseases but due to changing patterns of socioeconomic factors and urbanization, non-communicable diseases are increasing (4)

India is observing the phenomenon of crumbling family support systems like in countries China, Japan, and Singapore and other developed countries. A transition of traditional joint family system to the 
nuclear families has given rise to the concept of institutionalization or old age homes in India as well. ${ }^{(5)}$ Advancing age pose a challenge to morphological and physiological function of man. Old age is associated with ill health, physical and sensory impairment, heightened sensitivity and increased susceptibility to the diseases. Ageing is a series of parallel process related to one another ${ }^{(6)}$.

In sharp contrast to other health-promoting behaviors, physical activity declines progressively with age. As a result of inactivity, elderly persons experience preventable functional decline, loss of independence, and increased disease burden. Many lack the strength, flexibility, or endurance to rise from a chair, walk, or dress independently ${ }^{(7)}$. The major area of concern is the health of the elderly with multiple medical and psychological problems. Falls are one of the major problems in the elderly and are considered one of the "Geriatric Giants"(8).

In India, the life expectancy has steadily gone up from 32 years at the time of independence to over 63 in 2001. The elderly experience changes in different aspects of their lives. Change in socio-economic status adversely affects the individual's way of life after retirement. The economic loss is due to a change from salary to pension or unemployment leading to economic dependency on children or relatives. A feeling of low selfworth may be felt due to the loss of earning power and social recognition. This state of mind is harmful ${ }^{(9)}$. The problems of the aged differ not only between nations but also within nations and between groups.

All the aspects of "Health status", "Lifestyle", "Life satisfaction", "Mental health" and "Well-being" together reflects the multidimensional nature of Quality of Life in an individual. Conventionally, there are two processes considered to be involved in the aging of a population, aging at the base and aging at the apex of the population. The former results from a decline in fertility, the latter, mortality reduction among the elderly. In India, both processes are recent phenomena ${ }^{(10)}$. This paper seeks to look into medical, social and psychological of aging in Nanded.

\section{Aim And Objectives}

To study the medical and psychosocial problems among geriatric population.

\section{Materialand Methods}

Study Setting: The study was conducted in Urban Health Training Centre Shivaji Nagar, Nanded which include eight slum areas catering health care services to around 59586 populations of all ages

Reference Population: Elderly population of age 60 years and above of field practice area.

Study Participants: three hundred and fifty four individuals aged 60 years

Study Design and Sampling: A multi diagnostic camp based approach was used to study the health status of the geriatrics. Study of medical and psychosocial problems among population aged 60yrs and above was carried out using pre designed pre tested questionnaire.

Inclusion Criteria: People of age 60 years and above and willing to participate in the study with consent Exclusion Criteria: Those who were not willing to participate in the study and seriously ill patients.

Strategy: The study was conducted during multi diagnostic camp arranged on the WHO day, $7^{\text {th }}$ April 2012 having theme "Aging and Health". Data was collected using WHOQOL BREF scale (Field trial, WHO 1996). The participants were interviewed after obtaining verbal consent in local language. Information was collected on socio-demographic factors and four domains, that is, physical, psychological, social relationship and environmental. For comprehensive assessment, one item from each of 24 facets contained in the WHOQOL-100 had been included; in addition two items from the QOL and general health facets were also included. Each item was rated on five point scale (1-5). The raw score of each domain was calculated, and then transferred into range between 0-100. Five percent of questionnaires were rechecked by another author to assess the quality of data.

Statistical Analysis: The data were tabulated and analyzed using the statistical package of SPSS 13.0 version. Proportion test was used to test the significant at $\mathrm{P}<0.05$ and $\mathrm{P}<0.01$

\section{Results}

In present cross-sectional study at Urban Health and Training Centre, Shivaji Nagar, Nanded, 354 subjects $>60$ years of age were studied. Amongst them 198 were males and 156 were females.75\% subjects were in60-69years age group, 25\% were $>70$ years age (Table No. 1). Majority of the population under study belonged to Buddhist Community (56.44\%).38.7\% study population belonged to Muslim and $15.25 \%$ belonged to Hindu. $74 \%$ respondents were illiterate, it is more common in females $(82.69 \%)$ as compared to males $(67.85 \%)$. $61.86 \%$ subjects belongs to class $\mathrm{V}$ by kuppuswamy socioeconomic classification while $4.23 \%$ subjects belongs to class I. 
Table 1. Age and sex wise distribution of study population.

\begin{tabular}{|l|l|l|l|}
\hline Age group (years) & Male (\%) & Female (\%) & Total (\%) \\
\hline $60-64$ & $68(34.34)$ & $60(38.46)$ & $128(36.15)$ \\
\hline $65-69$ & $86(43.43)$ & $52(33.33)$ & $138(38.98)$ \\
\hline $70-74$ & $29(14.64)$ & $27(17.30)$ & $56(15.81)$ \\
\hline $75-79$ & $11(5.55)$ & $10(6.410)$ & $21(5.93)$ \\
\hline $80+$ & $4(2.02)$ & $7(4.48)$ & $11(3.1)$ \\
\hline Total & $198(55.94)$ & $156(44.06)$ & $354(100.0)$ \\
\hline
\end{tabular}

Table no. 2 shows morbidity profile of geriatric populations. Hypertension was seen in $43 \%$. It is more common in females $(59.61 \%)$. Visual disturbances were seen in $62 \%$ of study population. It was more common in males $(65.6 \%)$. Osteoarthritis was seen in $28 \%$ of population. It is more commonly seen in females $(32.69 \%)$. Diabetes Mellitus was seen in $15.5 \%$ of population. It is more commonly seen in males (16.16\%).

Table 2: Morbidity wise distribution of subjects in Geriatric age group

\begin{tabular}{|l|l|l|l|}
\hline \multirow{2}{*}{ Disease Conditions } & \multicolumn{2}{|c|}{ Number of cases } & \multirow{2}{*}{ Total (\%) } \\
\cline { 2 - 4 } & Males (\%) & Females (\%) & \\
\hline Hypertension & $63(31.8)$ & $93(59.61)$ & $153(43)$ \\
\hline Diabetes mellitus & $32(16.16)$ & $24(15.38)$ & $56(15.73)$ \\
\hline Osteoarthritis & $48(24.24)$ & $51(32.69)$ & $99(28.0)$ \\
\hline Visual disturbances & $130(65.6)$ & $90(57.69)$ & $220(62)$ \\
\hline Gastrointestinal & $18(9.09)$ & $9(5.76)$ & $27(7.5)$ \\
\hline Others & $39(19.69)$ & $19(12.17)$ & $58(16.38)$ \\
\hline
\end{tabular}

According to Table No 3, Smoking was seen in $21.75 \%$ of the total study population. It was more common in males (38.17\%). Tobacco chewing was seen in $22.88 \%$ of the total study population. It was more common in males $(21.72 \%)$. Alcohol intake was seen among $10.45 \%$ of the total study population. It was more common in males (17.67\%). $44.92 \%$ study population did not have any addiction.

Table: 3 Addiction pattern among study subjects

\begin{tabular}{|l|l|l|l|}
\hline Addiction & Males (\%) & Females (\%) & Total (\%) \\
\hline Smoking & $74(38.17)$ & $3(1.92)$ & $77(21.75)$ \\
\hline Tobacco chewing & $43(21.72)$ & $38(24.35)$ & $81(22.88)$ \\
\hline Alcohol & $35(17.67)$ & $2(1.28)$ & $37(10.45)$ \\
\hline No Addiction & $46(23.24)$ & $113(72.44)$ & $159(44.92)$ \\
\hline Total & 198 & 156 & 354 \\
\hline
\end{tabular}

Table no. 4 shows distribution of study subjects according to the family compositions. $5.6 \%$ of the total study population lived alone. Males (6.56\%) more commonly live alone as compared to females (4.48\%). $8.47 \%$ of the total study population lived with spouse alone. Females $(9.61 \%)$ more commonly lived with spouse alone as compared to Males (7.57\%). $75.14 \%$ of the total study population lived with spouse and children. Females (75.56\%) more commonly lived with spouse and children as compared to Males (74.74\%). $10.73 \%$ of the total study population lived with children. Males $(11.11 \%)$ more commonly live with children as compared to females $(10.25 \%)$.

Table: 4 Distribution of study subjects according to Family Composition

\begin{tabular}{|l|l|l|l|}
\hline Family Composition & Males (\%) & Females (\%) & Total (\%) \\
\hline Alone & $13(6.56)$ & $7(4.48)$ & $20(5.6)$ \\
\hline With Spouse & $15(7.57)$ & $15(9.61)$ & $30(8.47)$ \\
\hline With Spouse and Children & $148(74.74)$ & $118(75.56)$ & $266(75.74)$ \\
\hline With Children & $22(11.11)$ & $16(10.25)$ & $38(10.74)$ \\
\hline Total & $198(55.94)$ & $156(44.06)$ & $354(100)$ \\
\hline
\end{tabular}

Table No.5 shows perception of elderly study subjects about various social and psychological factors related with attitude of family members towards them, their life, care, various problems, around $29.94 \%$ of 
elderly told that attitude of their family members towards them is respectful while $22.32 \%$ told that they are neglected specially while taking important decisions, illness, and about honors etc. majority from their daughter in laws. When asked about their view for now days or at previous times of their childhood, when was better care taken for elderly? Around $74.58 \%$ study subjects told that at previous times elderly were better taken care. The main problem during old age was health followed by economic problems. $62.43 \%$ subjects told that health related problems were more among them. In the old age, the better care taker during illness and in problems were spouse and daughters. Almost all the geriatrics appreciated their daughters for batter care during their illness. Around 29\% of the geriatrics told that during their illness, their daughters always care in by means of food supplementation, nursing care and moral support.

Table no.5: Perceptions of the elderly study subjects

\begin{tabular}{|l|l|l|l|}
\hline DESCRIPTION & MALE & FEMALE & TOTAL \\
\hline Attitude of Family Members Towards the Elderly Persons & $106(29.94 \%)$ \\
\hline Respectful & $57(28.79 \%)$ & $49(31.42 \%)$ & $169(47.74 \%)$ \\
\hline Normal & $96(48.48 \%)$ & $73(46.79 \%)$ & $79(22.32 \%)$ \\
\hline Neglect & $45(22.73)$ & $34(21.79 \%)$ & 354 \\
\hline TOTAL & 198 & 156 & $264(74.58 \%)$ \\
\hline Do you feel Elderly Persons were better taken care of before? & $90(25.42 \%)$ \\
\hline Yes & $135(68.18 \%)$ & $129(82.69 \%)$ & 354 \\
\hline No & $63(31.82 \%)$ & $27(17.31 \%)$ & $221(62.43 \%)$ \\
\hline Total & 198 & 156 & $94(26.56 \%)$ \\
\hline What the Elderly Persons felt as the Main Problems in Old Age & $39(11.01 \%)$ \\
\hline Health & $112(56.57 \%)$ & $109(55.10 \%)$ & 354 \\
\hline Economic & $56(28.28)$ & $38(19.19 \%)$ & \\
\hline Social Adjustment & $30(15.15 \%)$ & $9(4.55 \%)$ & $79(22.32 \%)$ \\
\hline Total & 198 & 156 & $103(29.1 \%)$ \\
\hline When Person is very old and needs help, who can be of best help? & $118(33.34)$ \\
\hline Sons & $35(17.68 \%)$ & $44(28.20 \%)$ & $54(15.26 \%)$ \\
\hline Daughters & $61(30.81 \%)$ & $42(26.92 \%)$ & 354 \\
\hline Spouse & $87(43.94 \%)$ & $31(19.88 \%)$ & $39(25 \%)$ \\
\hline Self & $15(7.57 \%)$ & 156 & \\
\hline Total & 198 & \\
\hline
\end{tabular}

\section{Discussion}

Our study result includes age group $65-69$ years $(38.98 \%)$, followed by $60-64$ years $(36.15 \%)$ and above 80 years of age $(3.1 \%)$. The sex distribution showed that males outnumbered $(55.93 \%)$ than females (44.06\%). Illiteracy was found to be more common in female population. Most of geriatric population was found to be unemployed. Most of subjects belonged to joint family with socioeconomic status V. Most of subjects were found to be financially dependent. It was due to illiteracy, unemployment and morbid conditions.

Most of male subjects (38.17\%) were found to be addicted to tobacco smoking in form of bidi. As observed by Pandve HT and Deshmukh $\mathrm{P}^{(11)}$, alcohol intake and smoking was seen only in males $(42.1 \%)$. Tobacco chewing was more common in females. Tobacco chewing was present in $68.4 \%$ of the male population and among females it was $17.7 \%$. Hypertensive subjects were smokers and tobacco chewers. $38 \%$ males were alcoholic. COPD was more common in smokers. Most of the subjects had disturbed sleep pattern, associated with morbid conditions, depression, loneliness, disturbed micturating habits. Very less subjects had physical exercise and hobbies.

Most of geriatric population lives with their spouse and children. As observed by, S Irudaya Rajan ${ }^{(12)}$, close to 60 percent of the male elderly live with their spouses, children and grandchildren; the corresponding percentage for the female elderly is only 42 percent. On the other hand, close to 50 percent of the female elderly live with their children and grandchildren (without spouse) and only 30 percent of the males live with their children and grandchildren but without their spouse ${ }^{(13)}$. This population feels confident than those who lives alone in financial crisis, and had better life.

Most of the subjects were not engaged in work for whole day, so neglected by their family members and feel loneliness, sadness, depression. As observed by, Rahul Prakash and S. K. Chaudhary ${ }^{(14)}$, total $42 \%$ elderly had psycho-social problems in which $21.05 \%$ males and $27.3 \%$ females had the problems of loneliness, $15.8 \%$ males and $20 \%$ females felt neglected/ ignored by their kins ${ }^{3}$.Very few subjects were related to social organization, if present those were males. 28 males were widower and 17 females were widows. Those who live with spouse had good relation with him/her and sexually satisfied.7 males were sexually dissatisfied, dissatisfaction was due to loss of spouse and psychological factors. Being single, without the life partner, it is not possible for them to discuss their personal problems with others. Our study shows that elderly were too easily irritated and gets easily upset as expected. Most of elderly worry about relation they have with their spouse and other people. It is more common in those who live alone. 
Cataract was more common condition $(62 \%)$ observed in study subjects followed by Hypertension (43\%). As observed by Pandave HT and Deshmukh ${ }^{(11)}$, Cataract was the most common morbid condition $(68 \%)$ present among the study subjects. Other common conditions were osteoarthritis (53\%), hypertension $(27 \%)$ and hemiplegia (7\%). In our study(15.73\%) subjects found receiving treatment for Diabetes mellitus. As observed by, SPS Bhatia and HM Swamy ${ }^{10}$, the prevalence of diabetes mellitus was found to be $11.9 \%$ in the aged persons, and it was significantly more in females than in males ${ }^{(15)} .7 .5 \%$ were having GI illness. Morbidity was more common in low socioeconomic class subjects. $2 \%$ subjects received treatment for Tuberculosis. $28 \%$ subjects were having bony complaints. Emotional problems were observed in the $78 \%$ of the study subjects, $40 \%$ of the study subjects suffered from insomnia.

It is often claimed that ageing is accompanied by multiple illnesses and physical ailments. Besides physical illnesses, the aged are more likely to be victims of poor mental health, which arises from senility, neurosis and extent of life satisfaction. Elderly persons in the community not only suffer from physical ailments but also family and community neglect and economic hardship. For chronic cases, disease has to be explained to the family and to the patient, so that more endurance can be habituated. Our experience in working with elderly population in the project area made us realize that motivation and involvement of family members and community are the two pillars of geriatric care and is a challenging task. Most of subjects did not achieve standard of living and social status they expect. Therefore, it is required to recognize these problems and carry out activities to increase the awareness for more utilization of geriatric welfare services.

\section{References}

[1]. Jeyalakshmi S, Chakrabarti S, Gupta N. Situation analysis of the elderly in India central statistics office ministry of statistics \& programme implementation. Government of India; June 2011.

[2]. Shivamurthy M, Wadakannavar AR. Care and support for elderly population in India: result from a survey of aged in rural north karnataka (india); Aug 2001.P. 11.

[3]. Sandhya GI. Geriatric depression and related factors: a cross sectional study from rural community in south kerala. Journal of Indian acadamy of geriatric $2010 ; 6: 61-3$

[4]. Manda PK, Chakraborty D,Manna N, Mallik S, Chaterjee C. Disability among Geriatric females: an uncured agenda in rural India. Sudanese journal of public health 2009;4

[5]. Hutton D. Older People in Emergencies: Consideration for action and policy development. WHO library cataloguing-in-publication data, WHO; 2009.

[6]. Tyagy R, Kapoor S, Kapoor AK. Enviornmental influence and health status of elderly. The open anthropology journal 2008; 1;14-8.

[7]. Philip EM, Schnieder JC, Mercer GR. Motivating elderly to initiate and maintain exercise. arch phys med rehabil 2004 Jul;85(3).

[8]. Krishnaswamy B. Falls in elderly national/regional review, India.

[9]. Lena A, Ashok K, Padma M, Kamath V, Kamath A. Health and Social Problems of the Elderly: A Cross-Sectional Study in Udupi Taluk, Karnataka. Indian Journal of Community Medicine 2009 Apr;34(2).

[10]. Bhatia SP, Swami1 HM, Thakur JS, Bhatia V. A Study of Health Problems and Loneliness Among the Elderly in Chandigarh. Indian Journal of Community Medicine 2007 Oct; 32(4).

[11]. Pandve HT, Deshmukh P. health survey among elderly population residing in an urban slum of Pune city. journal of the Indian academy of geriatrics 2010;6:5-8.

[12]. Prakash R, Choudhary SK, Singh US. A study of morbidity pattern among geriatric population in an urban area of udaipur rajasthan. Indian Journal of Community Medicine 2004 Jan-Mar;29(1).

[13]. Mudey A, Ambekar S, Goyal RC, Agarekar S, Wagh VV. Assessment of quality of life among rural and urban elderly population of Wardha district, Maharashtra, India. Ethno med 2011;5(2):89-93.

[14]. Chanana HB, Talwar PP. Aging in India: its socioeconomic and health implications. Asia-pacific population journal 2000; 2(3).

[15]. Rao PM. Economic and financial aspects of ageing in India, (A paper presented at International Institute on Ageing), UN, Malta 